\title{
Experimental Characterization of a Passive Emergency Heat Removal System for a GenIII+ Reactor
}

\author{
Lorenzo Santini, Davide Papini, and Marco E. Ricotti \\ Department of Energy, CeSNEF-Nuclear Engineering Division, Politecnico di Milano, Via La Masa, 34, 20156 Milano, Italy \\ Correspondence should be addressed to Davide Papini, davide.papini@mail.polimi.it
}

Received 28 April 2009; Accepted 3 October 2009

Academic Editor: Dubravko Pevec

Copyright ( $) 2010$ Lorenzo Santini et al. This is an open access article distributed under the Creative Commons Attribution License, which permits unrestricted use, distribution, and reproduction in any medium, provided the original work is properly cited.

\begin{abstract}
Among the several types of passive safety systems adopted in new generation reactor designs, the experimental investigation of a closed loop, two-phase flow, natural circulation system is depicted. Emergency Heat Removal Systems (EHRSs) based on this solution are envisaged as safety-engineered features for advanced nuclear reactors, as in the IRIS reactor. An experimental facility simulating one EHRS-like loop has been built and operated at SIET labs in Piacenza (Italy). The facility is a natural circulation, sliding pressure, and electrically heated loop, with a helical coil steam generator as a heat source and a horizontal tube pool condenser as a heat sink. A steady-state analysis is provided to characterize the system behaviour and its key parameters. Because of the loop limited volume, oscillations of the main parameters (temperatures, flowrate, pressure) may be expected. The oscillating phenomena detected during the experimental campaign are discussed; a reasonable explanation is at last proposed.
\end{abstract}

\section{Introduction}

The innovative passive safety systems of advanced LWRs are based on natural laws, such as gravity and natural circulation [1]. They can be considered more reliable than active systems, since the lack of mechanical moving parts or other active components should reduce the probability of hardware failure.

Natural Circulation (NC) principle has been widely adopted in the past in several power conversion systems. Subcritical fossil fuelled power stations use NC as boiler flow driving mechanism, with the great advantage of a higher simplicity and of the reduction in operation costs related to the absence of pumps. In the nuclear field, pressurized water reactors use the same principle in U-tube steam generators. In recent years, NC has become very attractive even for emergency core cooling applications [2], relying on elements which always exist in a nuclear reactor: the heat source, the heat sink, the piping, and the gravity law.

The apparent simplicity of this physical principle in reality covers the complexity of the phenomena mutually interacting in a natural circulation loop $[3,4]$ : operating pressure, flowrate, flow quality, and heat transfer coefficients are all linked together. The behaviour of the NC passive systems usually entails oscillations in the thermal-hydraulic parameters, for example, the flowrate, hence leading to possible fluid dynamic instabilities. In particular, the problem of thermal-hydraulic instabilities [5] is one of the most crucial drawbacks on natural circulation systems. Instabilities could cause oscillations of the main loop parameters, inducing mechanical and thermal fatigue problems as well as making the system unable to perform its duty due to excessive deviations from the expected behaviour. For passive systems, it is thus necessary to introduce the concept of "functional failure" [6], considering the possibility that the loads will exceed the capacity in a reliability physics framework. To give an example, too high frictional pressure drops could cause a cancellation of loop driving force, preventing the system to accomplish its goal.

IRIS reactor [7] belongs to the innovative NPPs making an extensive use of natural circulation principle for safety purposes. IRIS is a low/medium power $\left(335 \mathrm{MW}_{\mathrm{e}}\right)$ pressurized water reactor for electricity production developed by an international consortium led by Westinghouse. IRIS 


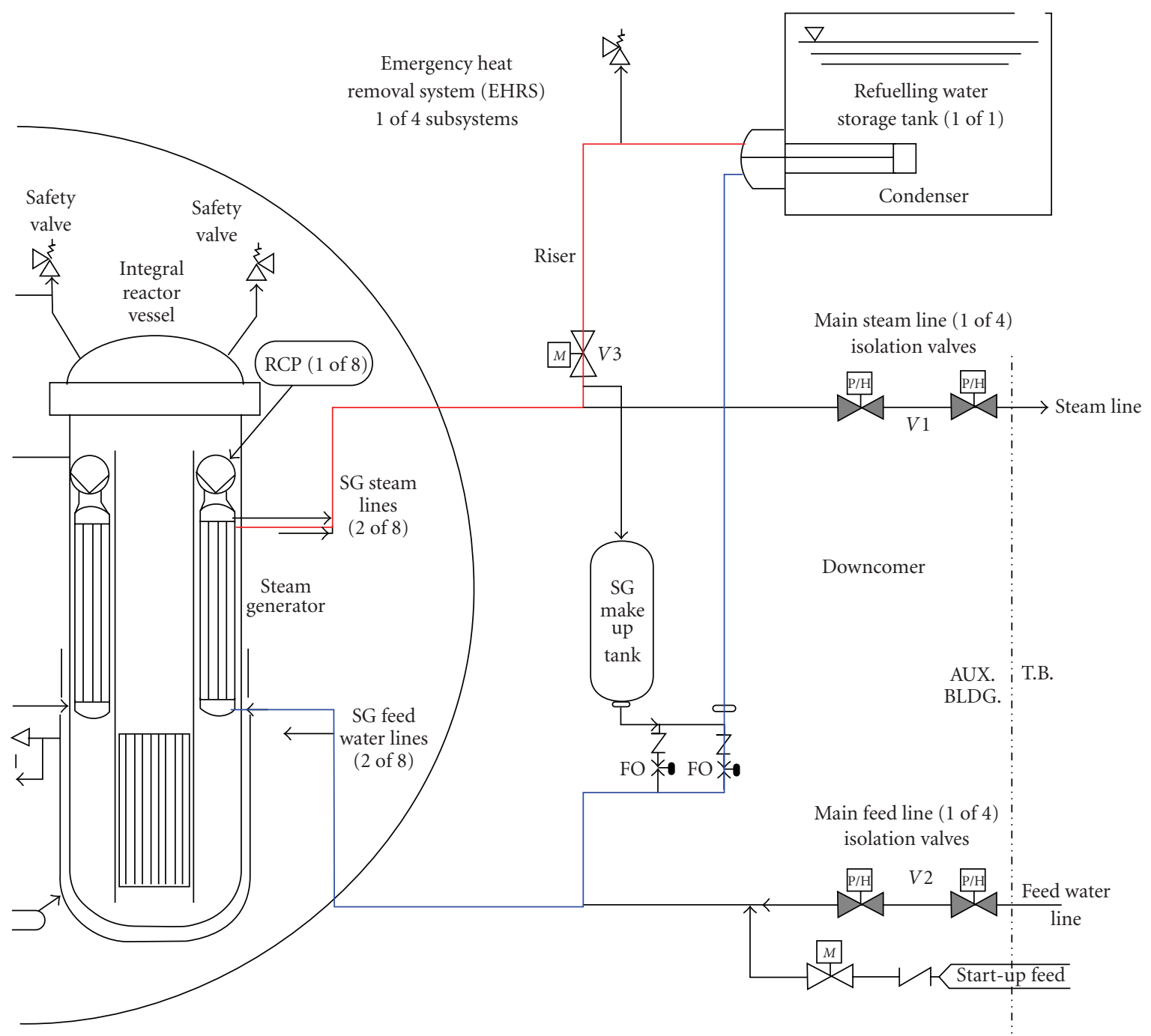

FIGURE 1: Sketch of IRIS emergency heat removal system (EHRS).

development started in late 1999 as part of the NERI program and has rapidly progressed to a nuclear reactor design with market entry targeted for deployment in the 2012-2015 time frame. The plant conceptual design was completed in 2001 and the preliminary design is currently underway. The preapplication licensing process with NRC started in October, 2002 and IRIS is one of the designs considered by US utilities as part of the ESP (Early Site Permit) process.

The main safety system of IRIS reactor is the Emergency Heat Removal System (EHRS), aimed to transfer core decay heat and sensible heat from the reactor coolant to the environment during transients, accidents, or whenever the normal heat removal paths are lost. It consists of four trains, each provided with a pair of steam generators (heat source), a hot leg (loop riser), a heat sink composed by a heat exchanger bundle submerged in the Refuelling Water Storage Tank (RWST), and a cold leg (downcomer), which closes the loop by bringing cold condensed water to the steam generators (Figure 1). Each of the four IRIS EHRS loops [8] is connected to one of the four steam and feedwater lines in the penetration area outside the containment (two of them are required to provide sufficient heat removal to match core decay heat). During normal plant operations V1 and V2 valves are open and V3 valve is closed (Figure 1); preheated water coming from the regeneration line is pushed into the steam generator where it is evaporated, slightly superheated, and sent to the turbine. If a reactor trip occurs, the core decay heat will be normally removed by the SGs thanks to the start-up feedwater system and the steam will be directed to the condenser via the steam dump valves. In case of malfunctioning of the start-up feedwater system, the EHRS is available to remove decay heat by means of the closure of $\mathrm{V} 1$ and V2 valves and the opening of V3 valve.

The challenge in analyzing the complex physics involved in the behaviour of a natural circulation loop requires relying not only on sophisticated modelling tools, for example, best estimate codes, but also on suitable experimental facilities, fundamental tools to provide data for validation of computer 
codes and safety system design. In this paper the results of an experimental campaign on a facility simulating a twophase, natural circulation, closed loop, sliding pressure safety system, similar to the type adopted for IRIS EHRS, are presented. As a preliminary step, a steady-state analysis has been performed to characterize the system behaviour. No accidents/transients have been investigated, the main goal being the dynamics of the loop at given primary thermal power to be rejected to the heat sink, at different system configurations (e.g., water mass inventories into the loop). A specific feature of the system and the facility is the closed loop, sliding pressure behaviour. Usually, in innovative BWR [9] and PWR [10, 11] designs the two-phase NC loops for passive safety systems are connected to large primary volumes, that is, the primary circuit, acting as a large expansion volume similar to a pressurizer. In the IRIS EHRS the loop is limited in volume since the in-pool condenser is directly connected to the helical coil steam generator tube bundle, hence a small volume when compared with the above mentioned configurations. It is expected that a dynamics with large pressure variations might occur, with possible feedbacks on the general behaviour. Moreover, the water mass inventory entrapped into the loop when the isolation valves activate should affect the system behaviour in a more sensible way with respect to the mentioned BWRs and PWRs safety systems, where larger mass inventories are expected.

The main simplification adopted in the facility is the imposed electrical power to obtain the heat source simulation, instead of the imposed temperature given by primary fluid, as in the real safety system. Although not strictly representative of the real loop conditions, it allows investigating a preliminary stability level for the system, apart from the thermal coupling with the primary loop which could introduce further complexity. Anyway, a useful experimental database for model validation is one of the main results.

\section{The Experimental Facility}

The IES facility (IRIS EHRS Simulator) was built and operated at SIET labs in Piacenza, as an extension of an electrically heated test section used for the investigation on the full-scale helical-coil steam generator tube [12]. The experimental loop is composed by a heat source, a riser, a heat sink, and a downcomer (Figure 2). It is scaled 1 : 1300 on power with respect to the real one, whereas it is full scale on height $(\sim 20 \mathrm{~m})$ and on thermal-hydraulic conditions (pressure and temperature). The full height allows reproducing the driving force.

The heat source is the electrically heated steam generator, previously built for the study of two-phase pressure drops and critical flux in the helical-coil. The tube, as well as the piping, is thermally insulated by means of rock wool. The thermal losses were measured via runs with single phase hot pressurized water flowing inside the steam generator and estimated as a function of the temperature difference between external tube wall and the environment. The riser is a $21.3 \mathrm{~m}$ long AISI 316 stainless steel tube with an inner

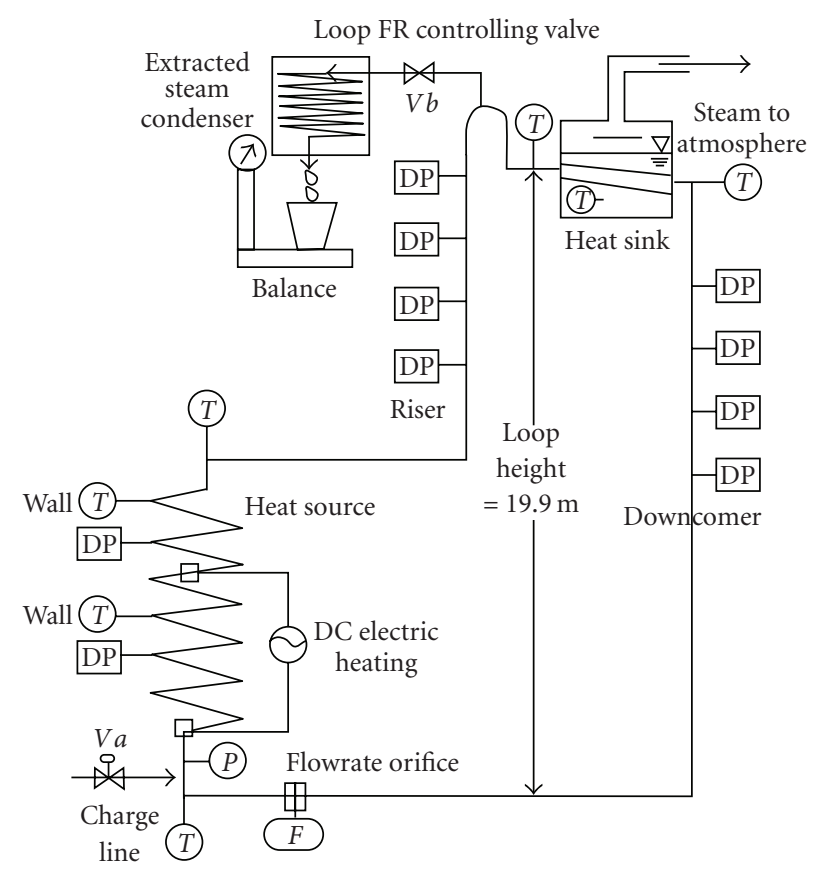

FIGURE 2: Sketch of IRIS EHRS Simulator facility (IES) at SIET labs.

diameter of $20.93 \mathrm{~mm}$ and an outer diameter of $26.67 \mathrm{~mm}$. Downcomer tube is a $31.8 \mathrm{~m}$ long AISI 316 stainless steel tube with the same dimensions as the riser. Riser and downcomer diameters have not been scaled with respect to IRIS EHRS riser and downcomer expected pressure drops. The facility operates with one pool condenser tube, $1 \mathrm{~m}$ long with 59 and $73 \mathrm{~mm}$ of inner and outer diameters. The tube simulates a condenser with nearly horizontal tubes, inclined of $3^{\circ}$ (corresponding to an early IRIS EHRS condenser design). A different solution with vertical tube arrangement will be investigated in the near future. The condenser tube is submerged into a 250-liter pool. A metallic slab is placed few centimetres before the vapour release duct in order to reduce the presence of liquid droplets in the exiting steam. The evaporated water is continuously replaced, according to a pool water level control.

The quantities measured in the loop (more than 200 measuring points) are flowrates, pressures (absolute and differential), temperatures, and powers. The loop flowrate has been measured by a calibrated orifice ( $5 \mathrm{~mm}$ diameter) placed at steam generator inlet and instrumented with a differential pressure transducer calibrated at SIET-labs (all the measurement devices are calibrated at SIET certified lab, SIT certified) with an estimated maximum uncertainty of $2 \%$. The loop absolute pressure is measured at steam generator inlet via an absolute pressure transducer with a maximum uncertainty of $0.1 \%$. Differential pressure transmitters are placed along the steam generator tube, the riser as well along the downcomer, with the aim of evaluating the possible presence of two-phase mixture at condenser tube outlet. Fluid temperature measurements are obtained with $\mathrm{K}$-class thermocouples, with a maximum error of $0.4^{\circ} \mathrm{C}$ at $100^{\circ} \mathrm{C}$. They are located at steam generator inlet and outlet headers, 
TABLE 1: IES facility main geometrical data.

\begin{tabular}{|c|c|c|c|c|c|}
\hline & Inner diameter $(\mathrm{m})$ & Outer diameter $(\mathrm{m})$ & $\mathrm{L}(\mathrm{m})$ & $\alpha\left({ }^{\circ}\right)$ & $\mathrm{R}(\mathrm{m})$ \\
\hline Orifice & 0.01253 & $0.01715\left(3 / 8^{\prime \prime}\right.$ S40) & 0.56 & 90 & 0 \\
\hline Heated test section & 0.01253 & $0.01715\left(3 / 8^{\prime \prime} \mathrm{S} 40\right)$ & 24 & 14.3 & 0 \\
\hline Unheated test section & 0.01253 & $0.01715\left(3 / 8^{\prime \prime} \mathrm{S} 40\right)$ & 8 & 14.3 & 0 \\
\hline Upper header & 0.0381 & $0.04826\left(1.1 / 2^{\prime \prime} \mathrm{S} 80\right)$ & 1.1 & 0 & 0 \\
\hline Elbow & 0.02093 & $0.02667\left(3 / 4^{\prime \prime} \mathrm{S} 40\right)$ & 0.6 & 90 & 0.15 \\
\hline Horizontal riser & 0.02093 & $0.02667\left(3 / 4^{\prime \prime} \mathrm{S} 40\right)$ & 9.45 & 0 & 0 \\
\hline Elbow & 0.02093 & $0.02667\left(3 / 4^{\prime \prime} \mathrm{S} 40\right)$ & 0.2 & & 0.15 \\
\hline Vertical riser & 0.02093 & $0.02667\left(3 / 4^{\prime \prime} \mathrm{S} 40\right)$ & 10.7 & 87 & 0 \\
\hline Siphon & 0.02093 & $0.02667\left(3 / 4^{\prime \prime} \mathrm{S} 40\right)$ & 1 & & 0 \\
\hline Condenser & 0.059 & $0.073025\left(2.1 / 2^{\prime \prime} \mathrm{S} 80\right)$ & 1 & -3 & 0 \\
\hline Elbows & 0.02093 & $0.02667\left(3 / 4^{\prime \prime} \mathrm{S} 40\right)$ & 3 & & 0 \\
\hline Vertical downcomer A & 0.02093 & $0.02667\left(3 / 4^{\prime \prime} \mathrm{S} 40\right)$ & 9.45 & -90 & 0 \\
\hline Elbow & 0.02093 & $0.02667\left(3 / 4^{\prime \prime} \mathrm{S} 40\right)$ & 0.2 & & 0.15 \\
\hline Horizontal downcomer & 0.02093 & $0.02667\left(3 / 4^{\prime \prime} \mathrm{S} 40\right)$ & 8 & 0 & 0 \\
\hline Vertical downcomer B & 0.02093 & $0.02667\left(3 / 4^{\prime \prime} \mathrm{S} 40\right)$ & 9.23 & -85 & 0 \\
\hline Elbows & 0.02093 & $0.02667\left(3 / 4^{\prime \prime} \mathrm{S} 40\right)$ & 2.1 & & 0 \\
\hline Test section inlet header & 0.02664 & $0.0334\left(1^{\prime \prime} \mathrm{S} 40\right)$ & 1.1 & 0 & 0 \\
\hline
\end{tabular}

at condenser tube inlet and outlet, and inside the pool. The electrical power is measured via a digital instrument with a relative uncertainty of $2.5 \%$. The main geometrical data of the facility are summarized in Table 1.

2.1. The Filling Procedure. The constant volume of the loop makes its performance dependent on the water mass actually stored in it. The loop Filling Ratio (FR) is defined as the ratio between the total mass in the closed loop and the total mass of cold water that could be stored into the loop. The investigation of the effects of different FRs [13] is one of the main goals of the experimental campaign [14], since it is anticipated that this parameter deeply affects loop behaviour, in terms of heat rejection capability (in fluid heated systems) and working pressure.

In the real EHRS loop, the designed filling ratio would be obtained by properly timing the closure of the two valves which isolate the passive system from secondary circuit. In IES test section, a specific FR was obtained according to the following procedure, starting from an empty loop (with reference to Figure 2):

(i) $V a$ and $V b$ valves open: the loop is completely filled with cold water via an external feed pump (the total measured mass of cold water storable in the system was nearly $25 \mathrm{~kg}$ );

(ii) $V a$ valve closed;

(iii) warm up of the steam generator;

(iv) extraction, condensation, and weighting of the extracted water-steam;

(v) $V b$ valve closed when the desired FR is obtained;

(vi) operation of the loop at the desired power level conditions.
2.2. The Heat Losses Compensation. The larger surface over volume ratio of the facility with respect to the real system makes the thermal losses of riser and downcomer rather significant, notwithstanding the thermal insulation. These heat losses have been compensated by heating the riser and downcomer piping with an electrical wire and tuneable power. Since the heat losses are proportional to tube wall temperature, hence two-phase mixture temperature, hence system pressure, the suitable power needed to compensate the heat losses is a function of the system operating pressure. Therefore, a dynamic compensation was required, until the steady state was reached.

The inherent dynamic nature of the procedure and the time periods needed to run out the transient make the procedure quite time consuming. On the other hand, a precise evaluation of the heat losses is achievable by measuring the offset electrical power, according to the results of the first experiences with this compensating practice.

2.3. Test Matrix. The test matrix is composed of 45 runs, which allowed studying the variations of the following parameters: filling ratio $(0.18,0.31,0.49,0.61,0.79)$, electric power supplied to the fluid, noncondensable gas content, and riser/downcomer heat losses compensation. The summary of the investigated parameters is provided in Table 2.

The lowest tested filling ratio (FR equal to 0.18 ) did not permit to reach the maximum power value $(43 \mathrm{~kW})$ due to large amplitude instabilities and dryout inception occurred in the test section. As far as the highest filling ratio/power points (FR of 0.79 and power of $43 \mathrm{~kW}$ ) are concerned, it was instead not possible to compensate the thermal losses because of their too high values. 
TABLE 2: Test matrix on IES loop.

\begin{tabular}{llll}
\hline $\begin{array}{l}\text { Filling } \\
\text { Ratio (FR) }\end{array}$ & $\begin{array}{l}\text { Test section } \\
\text { electrical power } \\
(\mathrm{kW})\end{array}$ & $\begin{array}{l}\text { Heat losses } \\
\text { compensation }\end{array}$ & $\begin{array}{l}\text { Noncondensable } \\
\text { gas presence }\end{array}$ \\
\hline 0.18 & 13 & yes & no \\
& 23 & yes & \\
& 33 & yes & \\
0.31 & 23 & yes & no \\
& 33 & yes & \\
& 43 & yes & yes \\
0.49 & 23 & yes & \\
& 33 & yes & \\
& 43 & yes & no \\
0.61 & 23 & yes & \\
& 33 & yes & no \\
0.79 & 43 & yes & \\
& 23 & yes & \\
& 33 & no &
\end{tabular}

\section{Steady-State Results}

3.1. Effects of Test Section Power and Filling Ratio on System Pressure. The most important effect of test section electrical power on system behaviour, at constant FR, is the setup of loop working pressure. A physical explanation is related to the working principle of pool condenser, assuming a steady-state condition with an equal balance between power supplied to the fluid and power rejected to the pool. The general formula describing the heat sink performance is

$$
Q=U \cdot S \cdot \Delta T_{l m} .
$$

The only way for transferring a higher thermal power to the pool is to increase $U$ or $\Delta T_{l m}$ (or both). The possibility of increasing $U$ is very small due to the strong thermal resistance of tube wall (thickness of $7 \mathrm{~mm}$ ) and to the weak dependence of two-phase condensation and boiling heat transfer coefficients on flowrate. Thus, to increase the mean temperature difference implies an increase in loop pressure, being the pool water boiling temperature fixed by atmospheric pressure (neglected pool condenser outlet subcooling influence on the phenomenon).

FR effect is physically more difficult to explain, and it seems to be strictly linked to condenser outlet subcooling. Pool condenser outlet subcooling plays a key role in terms of the loop capacity in storing the water mass. High FRs turn into long subcooled zones both in the steam generator and in the condenser: usually these zones, together with the downcomer piping, host the largest amount of charged water, being small the mass stored in the two-phase zones due to the rapid grow of void fraction with quality. An increase of FR implies wider single-phase zones and higher subcooling at condenser outlet, which would result in principle in a reduction of the exchanging power capability. The rejected

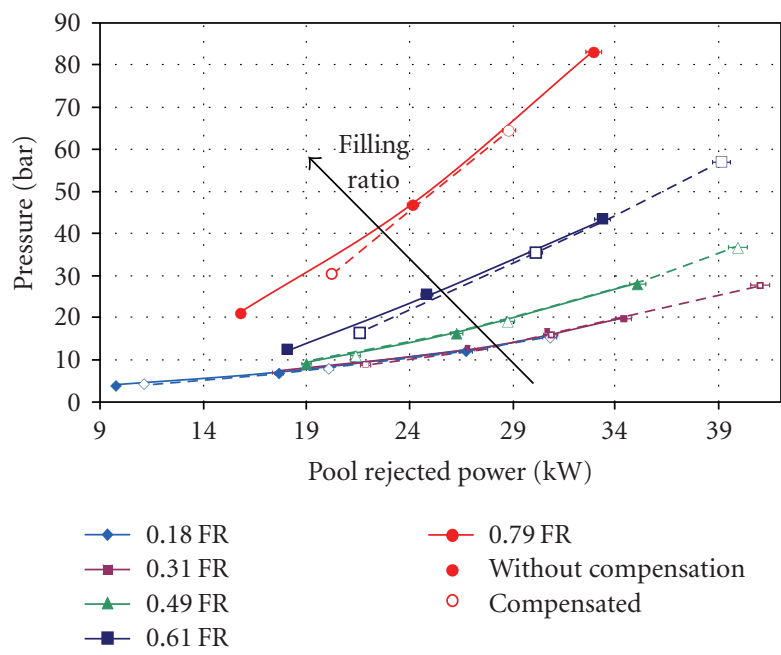

Figure 3: Effects of filling ratio and pool condenser rejected power on system pressure (both with and without heat losses compensation) [14].

power is anyway fixed by the electrical heating; thus $\Delta T_{l m}$ and hence loop pressure must increase.

Figure 3 resumes all the runs carried out on the loop for different values of power and FR, with and without riser and downcomer heat losses compensation: it is apparent that the system pressure increases as a function of FR and test section power (through pool rejected power).

The role of pool condenser rejected power as the controlling parameter on system operating behaviour is fundamental, whichever are electrical power and thermal dispersions (mainly dependent on loop pressure). System pressure variations are, as a matter of fact, always driven by (1), which needs to be respected in response to perturbations on the other loop parameters, as deeply explained even in the following section.

Besides, in order to summarize the experienced loop behaviour (Figure 3 data), a simple correlation between system pressure and pool condenser rejected power has been proposed, which is valid in the explored range of filling ratios (between 0.18 and 0.79 ):

$$
\frac{p^{0.7}}{T_{\mathrm{sat}}} \frac{\Delta h_{l g}}{\mathrm{Q}^{0.86}}=136 \cdot \mathrm{FR}^{2}-78 \cdot \mathrm{FR}+49,
$$

where the pressure $p$ is expressed in $\mathrm{kPa}$, the heat of vaporization $\Delta h_{l g}$ is expressed in $\mathrm{kJ} / \mathrm{kg}$, saturation temperature $T_{\text {sat }}$ is expressed in $\mathrm{K}$, and pool condenser rejected power $Q$ is expressed in $\mathrm{kW}$. System pressure is predicted with a mean error of $-1 \%$ and an RMS error of $7.3 \%$. These predictive capabilities, of course, have to be considered strictly limited to the specific characteristics of the loop investigated in this work.

3.2. Effects of Filling Ratio and Power on Pool Condenser Outlet Subcooling. The effects of FR and electrical power on pool condenser outlet subcooling are shown in Figure 4. Both 


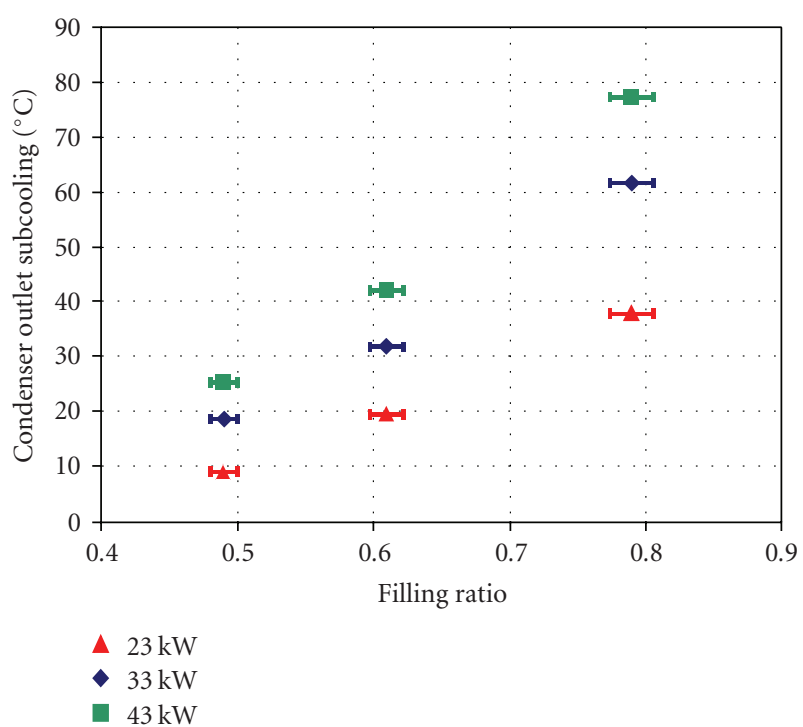

Figure 4: Effects of filling ratio and electrical power on pool condenser outlet subcooling (without heat losses compensation) [14].

the FR and the power increase the pool condenser outlet subcooling. The data at FR equal to 0.18 and 0.31 have been omitted, due to the presence of a two-phase mixture in the downcomer piping.

The central role of pool condenser power is still confirmed. Loop pressure variations are driven by the condenser outlet subcooling perturbations following a change in FR. As discussed in the previous section, an increase in FR, that is, loop mass content, induces the circuit to increase pool condenser and steam generator tube subcooling lengths, in order to allocate the increased mass. This augmented mass inventory cannot be otherwise hosted in the two-phase leg, since the void fraction shows typically high values (and moreover the downcomer is already filled with water). The increased subcooled zone lengths have a direct impact on pool condenser overall heat transfer coefficient; according to (1), $U$ must be smaller due to the increased importance of the liquid zone (which gives lower HTCs); thus an increase of mean logarithmic delta temperature between loop and pool water, the latest being always fixed at $100^{\circ} \mathrm{C}$, is needed. This demonstrates the necessary increase in system pressure from lower to higher FRs, which is consistent with the outcomes of Figure 3. Taking into account what discussed in Section 3.1, it is evident that both, effects of FR and of test section power on condenser outlet subcooling, require a corresponding increase in system pressure in order to achieve heat balance in steady state. Loop pressure acts therefore as the hidden thermal-hydraulic variable always involved when perturbing system input parameters.

In the previous reasoning the flowrate impact on pool condenser exchanging capabilities has been neglected. As it will be discussed in the next section, flowrate changes due to a change in power, but not monotonically, due to the complex interactions between downcomer gravitational driving force, riser gravitational counter-driving force, and

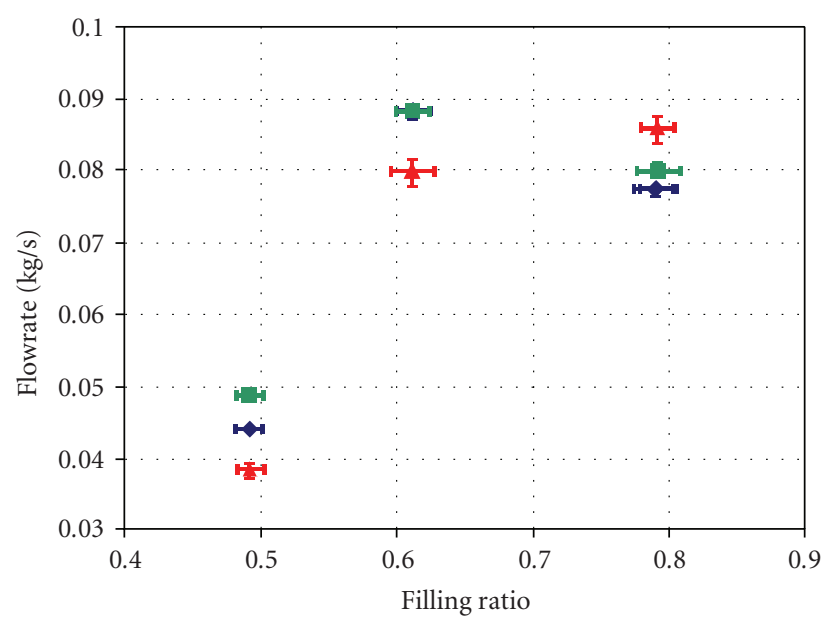

$$
\begin{array}{r}
\text { - } 23 \mathrm{~kW} \\
\text { - } 33 \mathrm{~kW} \\
\mathbf{1} 43 \mathrm{~kW}
\end{array}
$$

FIGURE 5: Effects of filling ratio and electrical power on system flowrate (without heat losses compensation) [14].

loop friction. By neglecting any change in loop flowrate with respect to thermal power, which is indeed small, the loop allocates a larger water mass content by increasing the pool condenser outlet subcooling.

\subsection{Effects of Filling Ratio and Power on Loop Flowrate.} Figure 5 shows that the effect of FR and electrical power on system flowrate is not monotonic. At low-medium FRs, an increase in power (considering pressure, FR and subcooling unchanged) increases the flow quality in the riser piping, reducing the gravitational counter-driving force. Thus, the flowrate would increase until a higher steam generator outlet quality reestablishes the balance between the friction pressure drops and the overall gravitational driving force (i.e., the density difference between riser and downcomer piping). This explanation is valid when the increase in power slightly changes steam generator inlet subcooling, that is, the case of the smallest value of FR (0.49) reported in Figure 5.

At higher FRs, the increased SG single phase zone length, as a consequence of the effect discussed in Section 3.2, makes the counter-driving force higher despite the increased power, causing a reduction in flowrate.

3.4. Noncondensable Gas Effect on System Pressure. In order to investigate the effect of the presence of noncondensable gases (e.g., air) on system behaviour, some tests were performed after the introduction of a certain amount of air into the system. The presence of noncondensable gas may come from several potential sources:

(i) the air naturally dissolved in the secondary circuit, due to a not perfect behaviour of the de-aerator of the secondary cycle; 


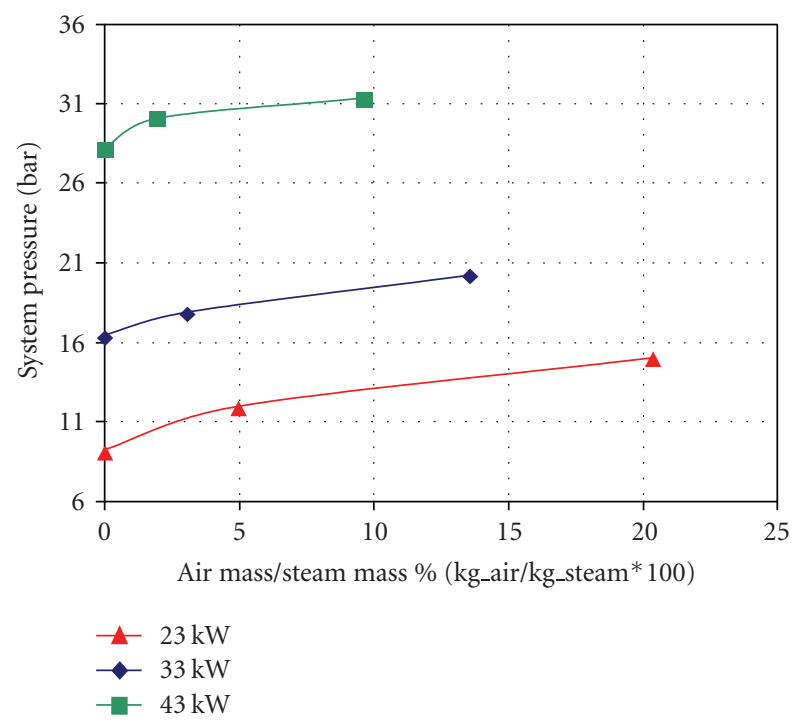

Figure 6: Noncondensable gas concentration effect on system pressure [14].

(ii) the introduction of helium or hydrogen into the secondary circuit, coming from primary circuit, due to a steam generator tube rupture or leakage;

(iii) the possibility of maintenance errors.

Condensation heat transfer coefficients are reduced if a noncondensable gas is added in the condensing fluid [15]. In fact, the gas collects at the interface between liquid film and condensing steam, reducing vapour partial pressure and thus its temperature (which drives the thermal exchange). This degradation in convective coefficients is more pronounced if system pressure is reduced and in stagnant mixtures rather than in forced convective condensation. A typical parameter introduced in order to quantify the amount of noncondensable gas is the ratio between the mass of air and the mass of steam $\left(M_{a} / M_{g}\right)$. The total quantity of steam, dependent on FR and system pressure, is obtained with the simplifying hypothesis that air content does not influence steam presence. Therefore, the loop is schematized as a volume with a defined portion occupied by liquid and the remaining portion by steam in saturated conditions, resulting

$$
M_{g}=\frac{V_{\text {loop }}-v_{l} \cdot \mathrm{FR} \cdot M_{0}}{v_{g}-v_{l}},
$$

being $M_{0}$ the maximum mass of liquid storable in the loop in cold conditions $(\approx 25 \mathrm{~kg})$.

The effect of noncondensable gas presence on system pressure is summarized in Figure 6. Air mass over steam mass ratio covered a range from $0 \%$ to $20 \%$, though the highest values must be considered not realistic in real system operation and were achieved only with the aim of emphasizing noncondensable content effect on system performance. The degradation of heat transfer coefficients at pool condenser tube results in a system pressure increase.
The effect is marked just with the first percentages of air introduced into the loop, as confirmed by the jump in pressure corresponding to noncondensable gas collecting at interface between saturated liquid and saturated steam; then such effect has to be considered small, being the rate observed equal to 0.2 bar of pressure increase every $1 \%$ of air content increase, and almost independent on the power level investigated.

\section{Limiting Boundaries for Loop Filling Ratio}

Simple considerations allowed identifying the effects of the main thermal-hydraulic parameters, especially water mass content, on loop steady-state conditions. As far as the dynamic oscillating behaviour of the loop is concerned, typical for a natural circulation system, a performance map has been obtained, where the limiting working conditions of the closed loop system are referred to the FRs and are function of system pressure, hence of thermal power to be rejected. Once an estimation of the loop pressure is obtained, the map allows defining the maximum and the minimum FRs ensuring a suitable dynamics for the system. It is important to point out that the map does not refer to a strict and thorough stability analysis, while the range of FRs leading to a suitable dynamics for the loop is related to engineering evaluations: working conditions, where flowrate inversion in the loop or two-phase mixture at steam generator inlet or loop completely filled with liquid occur, are evaluated as unfitted for a two-phase flow, closed loop safety system.

Oscillations of the circuit thermal-hydraulic parameters have been observed at the very low FRs experimentally investigated. Taking into account the SG tube, it can be assumed that a necessary but not sufficient condition for the stability is to have a negative thermodynamic quality at inlet: an increase in inlet quality, at fixed power, causes a wider two-phase zone length, leading to higher frictional pressure drops which are destabilizing. As previously stated, a boundary case to be avoided as prone to unstable behaviour is the operating condition with two-phase mixture entering the heated channel. This limit is in practice related to the volume of the downcomer with respect to the total volume of the loop. If the water initially stored into the loop is not enough to completely fill in the downcomer (i.e., small FR), the configuration previously described will occur. Obviously this minimum value must depend on system pressure because of the dependence of liquid density on pressure in saturated conditions. In order to quantify this limiting boundary by computing the minimum water inventory to be stored in the loop, the following simple conservative assumptions are made:

(i) homogeneous mixture flowing in the loop;

(ii) downcomer completely filled with liquid water at saturation temperature;

(iii) steam generator with complete evaporation of the mixture and linear increase of quality (from $x=0$ to $x=1$ ); 
(iv) riser filled with saturated steam;

(v) condenser tube with complete condensation and linear decrease of quality (from $x=1$ to $x=0$ ).

According to the previous assumptions, the masses stored in the four components of the loop (steam generator, riser, condenser and downcomer) are, respectively,

$$
\begin{aligned}
& M_{\mathrm{SG}}=V_{\mathrm{SG}} \frac{\ln \left(v_{g} / v_{l}\right)}{v_{g}-v_{l}}, \\
& M_{\text {riser }}=\frac{V_{\text {riser }}}{v_{g}}, \\
& M_{\text {cond }}=V_{\text {cond }} \frac{\ln \left(v_{g} / v_{l}\right)}{v_{g}-v_{l}}, \\
& M_{\text {down }}=\frac{V_{\text {down }}}{v_{l}} .
\end{aligned}
$$

The minimum value of the mass stored in the system in order to ensure a downcomer full of liquid water is thus

$$
M_{\min }(p)=M_{\mathrm{SG}}+M_{\text {riser }}+M_{\text {cond }}+M_{\text {down }},
$$

and the corresponding minimum filling ratio $\left(\mathrm{FR}_{\min }\right)$ for the loop is:

$$
\operatorname{FR}_{\min }(p)=\frac{M_{\min }(p)}{M_{0}}
$$

At very high FRs, that is, very high liquid contents, there must be a temperature hence a pressure in correspondence of which liquid specific volume is high enough to fill the entire loop volume. In this case, the degree of subcooling of the liquid leaving pool condenser allows the loop to store a higher quantity of mass, thus rising the maximum allowable FR. For a simple evaluation of the maximum FR, the entire loop is assumed filled with saturated liquid, except for the downcomer which is filled with subcooled water. With these assumptions the total mass stored is

$$
M_{\max }(p, \text { subcooling })=\frac{V_{\text {loop }}-V_{\text {down }}}{v_{l}(p)}+\frac{V_{\text {down }}}{v_{l_{-s c}}(\text { subcooling })}
$$

resulting in a maximum allowable FR equal to

$$
\operatorname{FR}_{\max }(p, \text { subcooling })=\frac{M_{\max }(p, \text { subcooling })}{M_{0}} .
$$

The map with loop maximum and minimum FR as a function of system pressure is drawn both for IES experimental facility and for IRIS EHRS loop design, as shown in Figures 7 and 8. It has to be intended as a quick tool to define the range for the mass to be charged into the system, in order to ensure a suitable functioning. The different shapes of lower curves in the two diagrams between IES facility and IRIS EHRS are due to their different volume distributions. In particular, in IES loop the steam generator volume is just

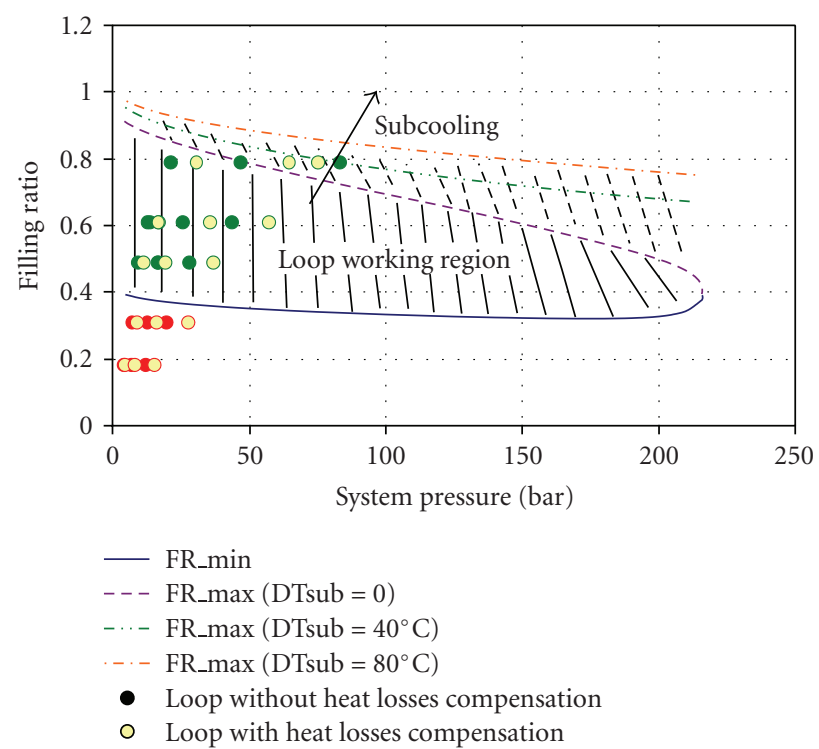

FIGURE 7: Filling ratio boundaries as a function of pressure and downcomer subcooling for IES loop.

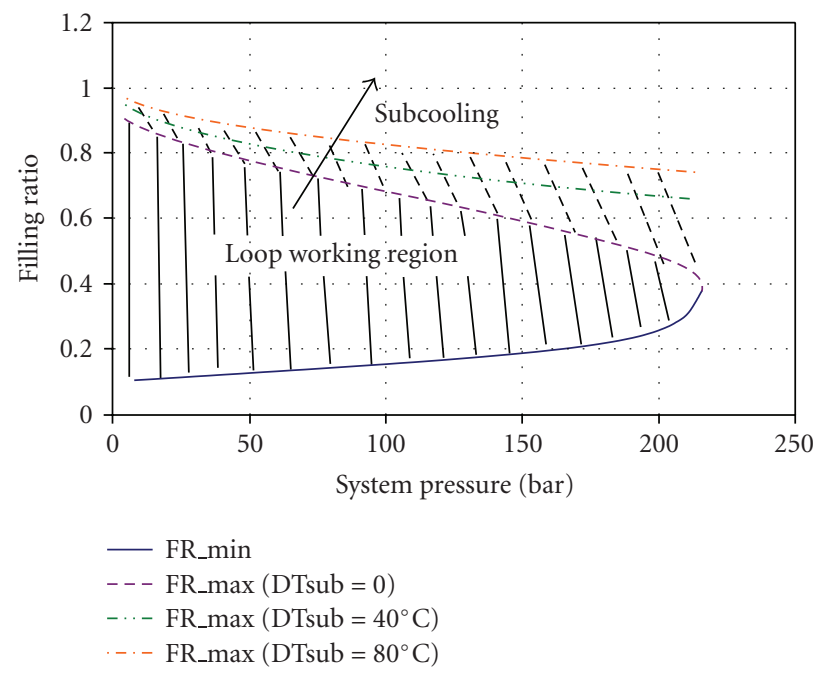

FIGURE 8: Filling ratio boundaries as a function of pressure and downcomer subcooling for IRIS EHRS loop.

$16 \%$ of total loop volume, whereas it is about $40 \%$ in IRIS EHRS loop. The increased importance of SG volume in the EHRS makes possible to store more mass in the component; thus the system minimum mass could increase passing from low to high pressures, due to the decrease of steam specific volume with pressure in (4). On the contrary, IES loop has a smaller SG volume, and hence an increase in system pressure has the main effect of reducing liquid inventory into the downcomer.

The map in Figure 7, related to IES facility, reports even the experimental data (FR versus system pressure) provided by the test matrix execution, already used to set up the graph in Figure 3. Both the cases with and without heat losses compensation are taken into account; it is evident how the 
compensation contributes to enhance system pressure. The dynamics and behaviour of the runs with FR equal to 0.49, 0.61 , and 0.79 always fall inside the loop working region, whereas the smallest FRs explored (0.18 and 0.31) are below the minimum acceptable FR. The measurements for these runs show as a matter of fact the presence of a two-phase mixture in the downcomer piping, hence leading to large uncertainties in the system flowrate monitoring.

\section{Stability Analysis}

Many Authors in the past studied the stability features of a natural circulation loop, both with analytical tools and with experimental works. Instability phenomena can be produced by appropriate combinations of geometrical and operating parameters, namely, loop height and length as well as heating power and friction. A pioneering work in this field is due to Welander [16], who showed these instabilities turn into the amplification of perturbed temperature slugs generated in the heated and cooled sections. These analyses have been recently resumed by Ambrosini et al., facing both analytically $[17]$ and with numerical codes $[18,19]$ the linear and nonlinear stability of a single-phase natural circulation loop. As far as the analytical approach is concerned, the main technique consists in linearizing the momentum and the energy equations as well as the boundary conditions, and adopting a first-order perturbation method. Suitable physical and geometrical parameters, evaluated in accordance with specific heat transfer laws and friction factor correlations, are used to completely identify the dynamic behaviour of the system. On this basis, stability maps [20] can be drawn, discriminating between stable and unstable regions according to the sign of the real part of the dynamic matrix eigenvalues (negative for stability and positive for instability conditions).

Other Authors referred the stability analysis to the interpretation of the dynamic flow oscillations $[21,22]$ which can appear in the loop. In particular, Jiang et al. experimentally studied a peculiar configuration which is named flow excursion [23], a new kind of static flow instability occurring at very low steam quality conditions and determined by the loop flow resistance and the internal driving head inside the natural circulation loop. Characteristic curves, operational curves, and bifurcation curves are the available methods to analyze these instabilities, as proposed by Yang et al. [24]. The same works show moreover how this flow excursion is prior to the low steam quality density wave oscillation [25], characterized by a dynamic interrelation between void fraction, pressure drops, and flowrate and by a strong coupling between the heated section and the heat sink condenser outlet.

In this paper, a particular kind of low-frequency oscillations, detected during the IES experimental campaign at the highest explored FRs, is discussed and interpreted in accordance with literature results. At the very low qualities which derive from a high FR, small flowrate variations can in fact cause large variations in riser void fraction, changing its gravitational pressure drops. The perturbation of loop

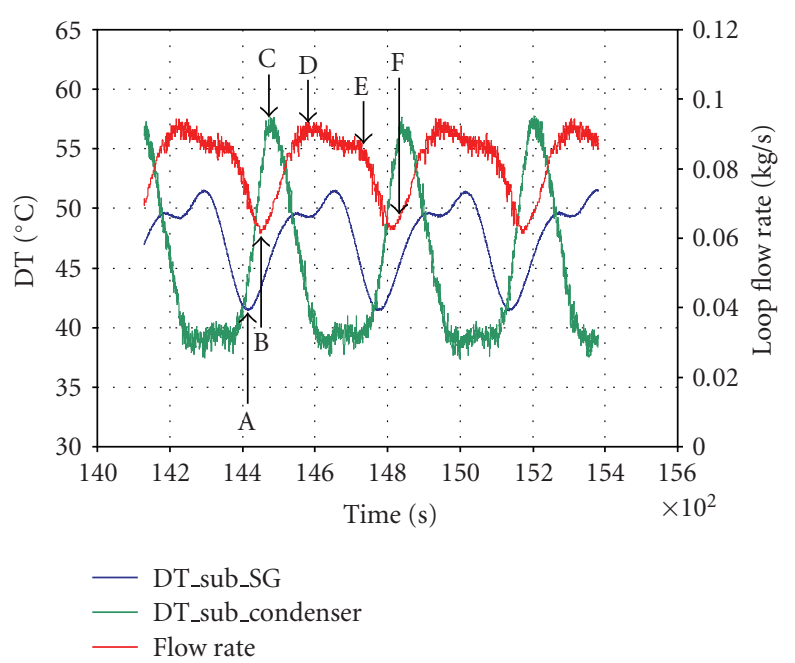

FIGURE 9: Low-frequency oscillations: steam generator inlet subcooling, pool condenser outlet subcooling, and loop flowrate as a function of time (Data obtained with power $=23 \mathrm{~kW}-\mathrm{FR}=0.79$ with heat losses compensation).

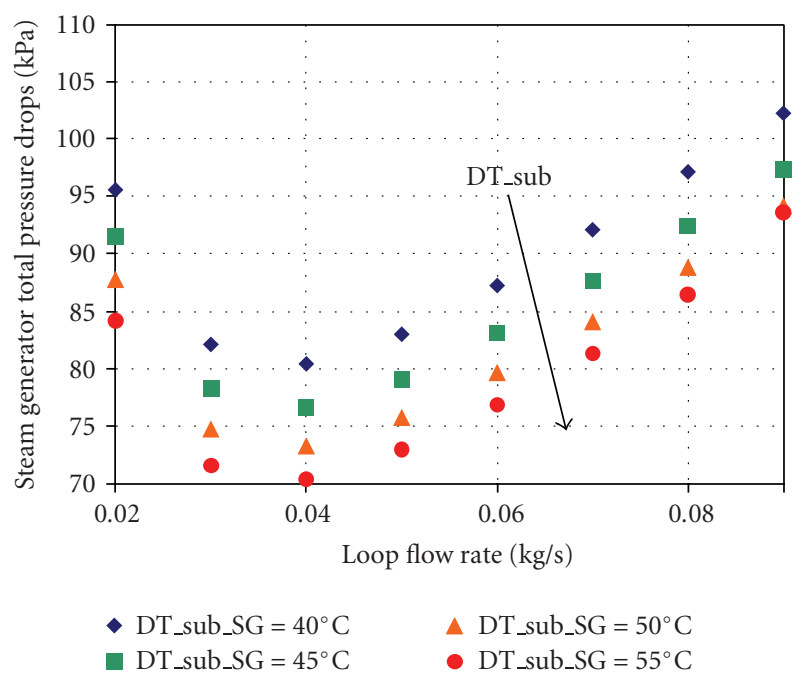

FIGURE 10: Steam generator pressure drops as a function of inlet subcooling (Data obtained with $p=30.5 \mathrm{bar}-$ power $=23 \mathrm{~kW}$ ).

pressure drops has a direct impact on the flowrate, influencing also pool condenser outlet subcooling. The coupling and the time delays between flowrate, pressure drops, and downcomer subcooling become the main responsible for the observed low-frequency oscillations. These oscillations occur at equilibrium conditions and do not affect the steadystate behaviour of the system, since the average values of the oscillating parameters are constant over a long-time period. They are mainly induced by the specific boundary conditions, that is, the imposed power at the heat source, the imposed temperature at the heat sink, and the unavoidable phase displacement due to the fluid running in the loop. 

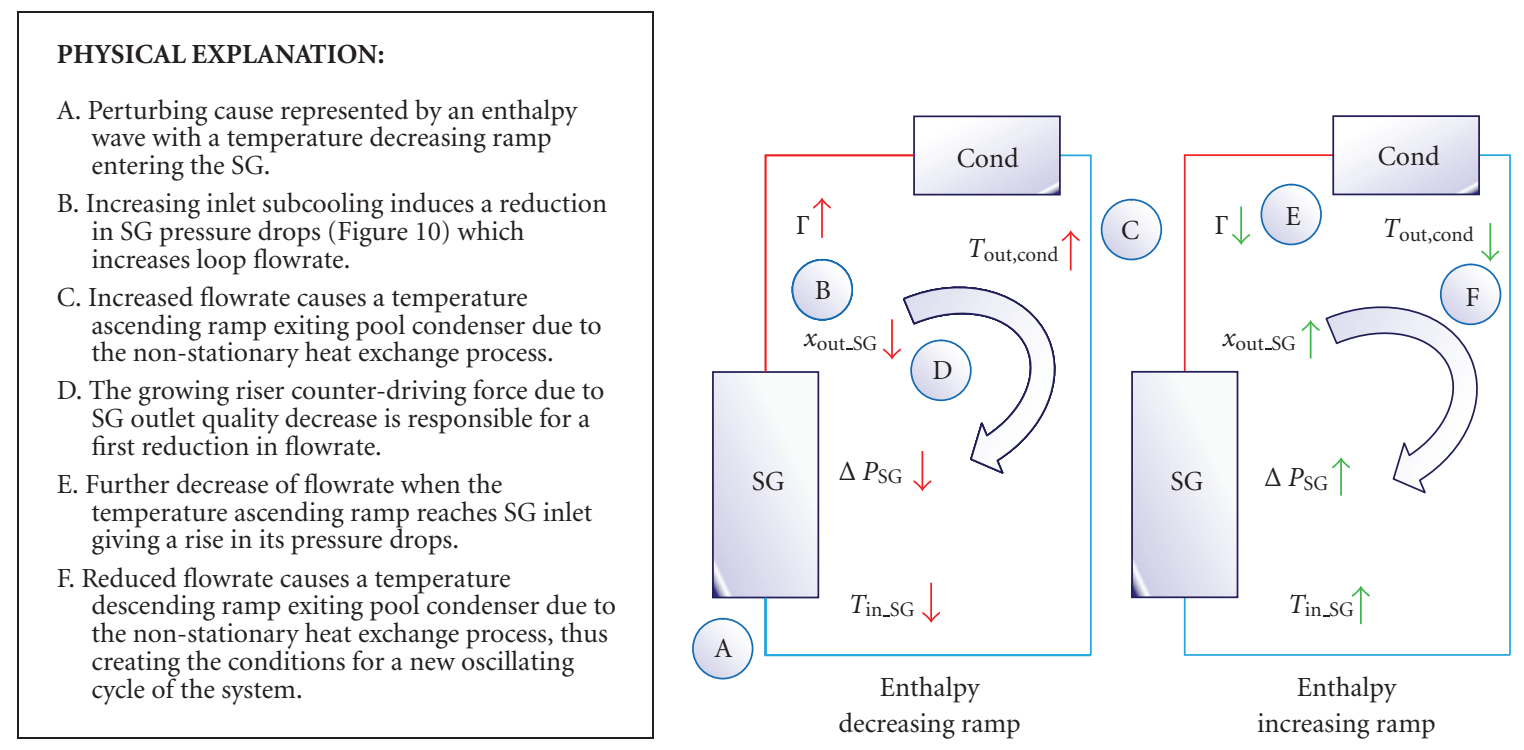

FIGURE 11: Schematic description of the physics involved in the low-frequency oscillations.

More in detail, the mentioned low-frequency oscillations, with periods of about 300 seconds, were detected only in the runs with the highest FR (0.79) and with the lowest power, that is, $23 \mathrm{~kW}$ and $33 \mathrm{~kW}$. In Figure 9 mass flowrate, pool condenser outlet temperature, and steam generator inlet temperature are plotted for a run in which such high-amplitude long-period phenomena were observed. The period of the oscillations is 347 seconds. The transit time for a particle flowing in the loop, that is, the time period needed to travel the entire closed loop, is

$$
\tau_{\text {loop }}=\frac{M}{\Gamma},
$$

being $M$ the stored mass and $\Gamma$ the flowrate. The run reported in Figure 9 refers to an FR of 0.79 , that is, a stored mass of $19.75 \mathrm{~kg}$, while the measured mean flowrate was $0.086 \mathrm{~kg} / \mathrm{s}$, resulting in a particle transit time equal to 230 seconds. The oscillation period reveals itself nearly 1.5 times the fluid transit time during that run. The similarity between the oscillation period and the particle residence time in the loop suggests that this oscillatory mode is somehow related to very slow enthalpy waves which travel in the loop with the same mean velocity of the mixture. These waves create a strong coupling between heated test section flowrate, riser pressure drops, and condenser outlet subcooling. This type of oscillations, widely investigated in mentioned works, for example, in [23], is probably related to the specific shape of the hot leg (steam generator and riser) characteristic (pressure drops dependence on loop flowrate, at different subcooling). Steam generator calculated pressure drops are shown in Figure 10. All the terms of pressure drops are included, except for the negligible acceleration term. The main result is that, everything else being the same, an increase in steam generator inlet subcooling reduces its total pressure drops.
Observing the curves reported in Figure 9, the similarity between SG inlet subcooling and loop flowrate supports the existence of a link between the two. In particular, SG inlet subcooling increase (point A) is always anticipating loop flowrate increase (point B), suggesting that the former is causing the latter. In order to understand the low-frequency oscillations propagation phenomenon, it is useful to consider a perturbation in the operating conditions, for instance, an enthalpy wave characterized by a decreasing temperature ramp exiting pool condenser. The enthalpy decreasing ramp entering the SG is equivalent to an increasing subcooling. According to the results of Figure 10, this subcooling wave will cause a reduction of SG total pressure drops which will increase loop flowrate (point B in Figure 9). The increased flowrate has the main effect of causing an ascending temperature ramp at pool condenser outlet (point C). This fact can be explained by a transient behaviour of the heat exchanger where, due to the increased flowrate, tube wall and liquid bulk are not able to reach a steady-state condition and have not enough time to exchange the power, resulting in a reduced extracted power and thus an increased outlet temperature. The increase in flowrate brings a decreasing SG outlet quality, which is then responsible for a first reduction in loop flowrate (from point $\mathrm{D}$ to point $\mathrm{E}$ ), due to the growing of riser counter-driving force caused by the increased gravitational pressure drops. Loop flowrate will be further reduced when the temperature ascending ramp, travelling along the downcomer, will reach steam generator inlet. A reduction in SG inlet subcooling has in fact the effect of increasing its total pressure drops, thus reducing the flowrate. This reduction in loop flowrate will finally cause an enthalpy wave in the form of a temperature descending ramp starting from the pool condenser, which will create the conditions for a new oscillating cycle of the system. The whole line of reasoning can be clearly followed relying on the schematic of Figure 11. 


\section{Conclusions}

The experimental campaign carried out in SIET labs on the IES facility simulating an IRIS EHRS-like loop has been described in the paper, the main goal being to investigate the influence of the mass inventory charged in the fixed volume system. The controlling parameter on system behaviour resulted to be pool condenser rejected power. Its balance equation is sufficient to explain how loop pressure responses to a change in loop FR and in test section electrical power. The most important effect of FR on loop performance is strictly linked to condenser outlet subcooling. High FRs turn into long subcooled zones both in the steam generator and in the condenser. The increased subcooled zone lengths have a direct impact on pool condenser overall heat transfer coefficient: the HTC is smaller due to the increased importance of single-phase heat transfer, resulting in an increase of mean logarithmic temperature drop, hence of pressure. The effects of FR and electrical power on system flowrate have been evaluated as well as the influence of the noncondensibles. The latter cause a reduction in condensation heat transfer, bringing to a slight loop pressure increase.

A simplified characterization of the facility has been proposed, to identify the FRs suitable for an effective behaviour of the system. The evaluation of the bounding values for FR has been summarized into a map, where the possible working conditions of the natural circulation loop are represented as a function of the achievable system pressure, both for IES experimental facility and for IRIS EHRS. The map is useful to quickly identify how much water has to be stored, according to the pressure level hence to the power to be rejected. The experimental runs on the IES facility and corresponding measurements and behaviour have confirmed the validity of the map.

A particular type of low-frequency oscillations, detected during the runs with the highest explored FR, has been investigated. These high-amplitude long-period oscillations are related to the particular boundary conditions of the system, that is, the imposed power at the heat source, the imposed temperature at the heat sink, and the unavoidable phase displacement due to the fluid running in the loop. At low qualities, a small SG inlet subcooling variation leads to sensible variations in SG and riser void fractions. The pressure drops influence loop flowrate which impacts also on pool condenser outlet subcooling. The coupling and the time delays between flowrate, pressure drops, and downcomer subcooling cause the observed phenomenon of low-frequency oscillations. The period of these oscillations (about 300 seconds) has been interpreted according to the concept of transit time for a particle flowing in the loop.

The explanation of the low-frequency oscillations proposed in the paper appears physically reasonable, being in accordance with all the observed phenomena and without any contradictions with the experimental results. Nevertheless, a confirmation of the mentioned cause-effect relations could come from a quantitative model of the system. The experimental campaign has indeed to be intended also as an important database useful to validate the accuracy of analytical models devoted to the dynamics of natural circulation thermosyphon loops. Both a simplified analytical model and a best-estimate (e.g., RELAP5) numerical model of IES facility are under development and will be validated on the experimental data.

\section{Acronyms}

BWR: Boiling water reactor

EHRS: Emergency heat removal system

ESP: Early site permit

FR: $\quad$ Filling ratio

HTC: Heat transfer coefficient

HX: Heat eXchanger

IC: Isolation condenser

IES: IRIS EHRS simulator

IRIS: International reactor innovative and secure

LWR: Light water reactor

NC: Natural circulation

NERI: Nuclear energy research initiative

NPP: Nuclear power plant

NRC: Nuclear regulatory commission

PWR: Pressurized water reactor

RMS: Root mean square

RWST: Refuelling water storage tank

SBWR: Simplified boiling water reactor

SG: Steam generator

SIET: Società informazioni esperienze termoidrauliche (company for information on thermal-hydraulic experimentation).

\section{Nomenclature and Symbols}

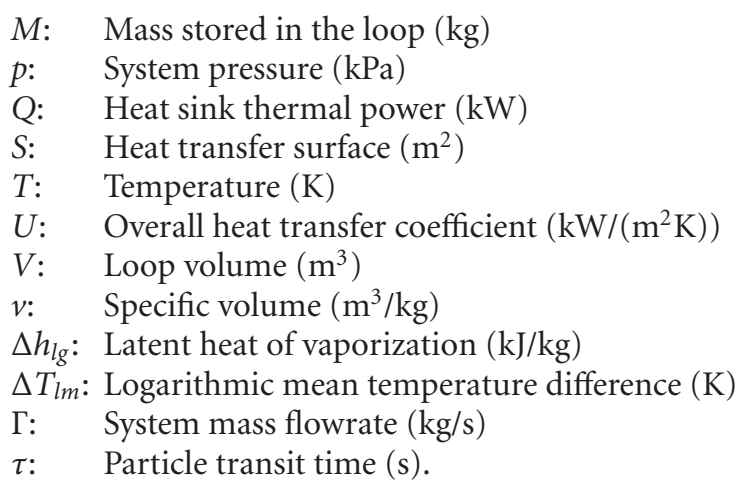

\section{Subscripts}
a: $\quad$ Air
cond: Pool condenser
down: Downcomer
$g: \quad$ Saturated steam
loop: Entire loop
$l$ : $\quad$ Saturated liquid
l_sc: Subcooled liquid
riser: Riser
sat: Saturation
SG: Steam generator. 


\section{Acknowledgments}

A special thanks to Professor Carlo Lombardi for his expertise, criticism, and invaluable help in following every part of the work. The Authors are grateful to Gustavo Cattadori, Andrea Achilli, and Stefano Gandolfi from SIET labs for their valuable collaboration and deep expertise. A dear thought also to Barbara Zito, worthy companion during the whole experimental campaign. Last but not least, the Authors are grateful to Mario Carelli and the colleagues of the IRIS project for the opportunity to work in such a stimulating and challenging adventure.

\section{References}

[1] IAEA-TECDOC-1281, "Natural circulation data and methods for advanced water cooled nuclear power plant designs," in Proceedings of a Technical Committee Meeting, Vienna, Austria, July 2000.

[2] Y.-J. Chung, S.-H. Yang, H.-C. Kim, and S.-Q. Zee, “Thermal hydraulic calculation in a passive residual heat removal system of the SMART-P plant for forced and natural convection conditions," Nuclear Engineering and Design, vol. 232, no. 3, pp. 277-288, 2004.

[3] P. K. Vijayan and A. K. Nayak, "Natural circulation systems: advantages and challenges," in Natural Circulation in Water Cooled Power Plants, IAEA-TECDOC-1474, 2005.

[4] N. Aksan, "Application of natural circulation systems: advantages and challenges II," in Natural Circulation in Water Cooled Power Plants, IAEA-TECDOC-1474, 2005.

[5] P. K. Vijayan and A. K. Nayak, "Introduction to instabilities in natural circulation systems," in Natural Circulation in Water Cooled Power Plants, IAEA-TECDOC-1474, 2005.

[6] L. P. Pagani, G. E. Apostolakis, and P. Hejzlar, "The impact of uncertainties on the performance of passive systems," Nuclear Technology, vol. 149, no. 2, pp. 129-140, 2005.

[7] M. D. Carelli, L. E. Conway, L. Oriani, et al., "The design and safety features of the IRIS reactor," Nuclear Engineering and Design, vol. 230, no. 1-3, pp. 151-167, 2004.

[8] A. Cammi and A. Cioncolini, "IRIS Passive Emergency Heat Removal System-PEHRS: state of the art design and RELAP model," IRIS Internal Report, Westinghouse Proprietary Class 2, 2003.

[9] J. Meseth, "Natural circulation and stratification in the various passive safety systems of the SWR1000," in Natural Circulation Data and Methods for Advanced Water Cooled Nuclear Power Plant Designs, IAEA-TECDOC-1281, 2002.

[10] F. D’Auria and M. Frogheri, "Natural circulation limits achievable in a PWR," in Natural Circulation Data and Methods for Advanced Water Cooled Nuclear Power Plant Designs, IAEATECDOC-1281, 2002.

[11] S. Zhang, "Experimental research and calculation method of natural circulation flow for AC600/1000," in Natural Circulation Data and Methods for Advanced Water Cooled Nuclear Power Plant Designs, IAEA-TECDOC-1281, 2002.

[12] L. Santini, A. Cioncolini, C. Lombardi, and M. Ricotti, "Twophase pressure drops in a helically coiled steam generator," International Journal of Heat and Mass Transfer, vol. 51, no. 19-20, pp. 4926-4939, 2008.

[13] Y. J. Park, H. K. Kang, and C. J. Kim, "Heat transfer characteristics of a two-phase closed thermosyphon to the fill charge ratio," International Journal of Heat and Mass Transfer, vol. 45, no. 23, pp. 4655-4661, 2002.

[14] C. Lombardi, M. Ricotti, L. Santini, and B. Zito, "Experimental results on a two-phase closed loop system," in Proceedings of Congresso Nazionale UIT sulla Trasmissione del Calore, Trieste, Italy, June 2007.

[15] J. C. Collier, Convective Boiling and Condensation, McGrawHill, New York, NY, USA, 1981.

[16] P. Welander, "On the oscillatory instability of a differentially heated fluid loop," Journal of Fluid Mechanics, vol. 29, pp. 1730, 1967.

[17] M. Maiani, W. J. M. de Kruijf, and W. Ambrosini, "An analytical model for the determination of stability boundaries in a natural circulation single-phase thermosyphon loop," International Journal of Heat and Fluid Flow, vol. 24, no. 6, pp. 853-863, 2003.

[18] W. Ambrosini and J. C. Ferreri, "Prediction of stability of one-dimensional natural circulation with a low diffusion numerical scheme," Annals of Nuclear Energy, vol. 30, no. 15, pp. 1505-1537, 2003.

[19] D. S. Pilkhwal, W. Ambrosini, N. Forgione, P. K. Vijayan, D. Saha, and J. C. Ferreri, "Analysis of the unstable behaviour of a single-phase natural circulation loop with one-dimensional and computational fluid-dynamic models," Annals of Nuclear Energy, vol. 34, no. 5, pp. 339-355, 2007.

[20] F. D'Auria, A. Del Nevo, and N. Muellner, "Insights into natural circulation stability," in Natural Circulation in Water Cooled Power Plants, IAEA-TECDOC-1474, 2005.

[21] C. Y. Wu, S. B. Wang, and C. Pan, "Chaotic oscillations in a low pressure two-phase natural circulation loop under low power and high inlet subcooling conditions," Nuclear Engineering and Design, vol. 162, no. 2-3, pp. 223-232, 1996.

[22] J.-T. Hsu, M. Ishii, and T. Hibiki, "Experimental study on two-phase natural circulation and flow termination in a loop," Nuclear Engineering and Design, vol. 186, no. 3, pp. 395-409, 1998.

[23] S. Y. Jiang, Y. J. Zhang, X. X. Wu, J. H. Bo, and H. J. Jia, "Flow excursion phenomenon and its mechanism in natural circulation," Nuclear Engineering and Design, vol. 202, no. 1, pp. 17-26, 2000.

[24] X. T. Yang, S. Y. Jiang, and Y. J. Zhang, "Mechanism analysis on flow excursion of a natural circulation with low steam quality," Nuclear Engineering and Design, vol. 235, no. 22, pp. 23912406, 2005.

[25] S. Guanghui, J. Dounan, K. Fukuda, and G. Yujun, "Theoretical and experimental study on density wave oscillation of twophase natural circulation of low equilibrium quality," Nuclear Engineering and Design, vol. 215, no. 3, pp. 187-198, 2002. 

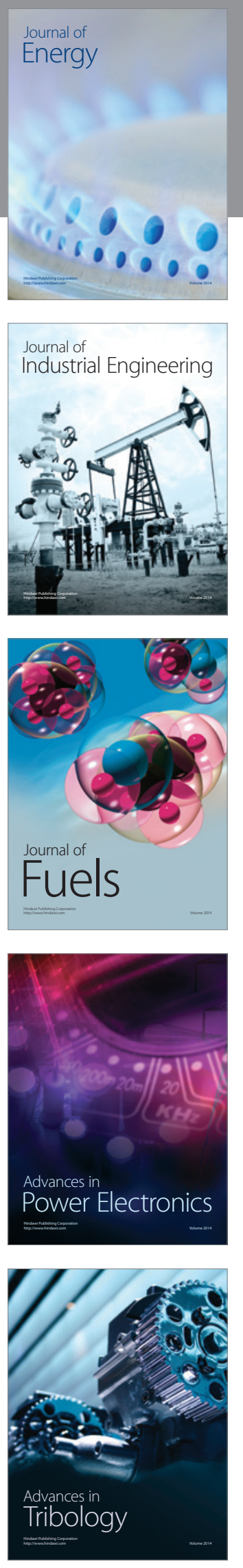
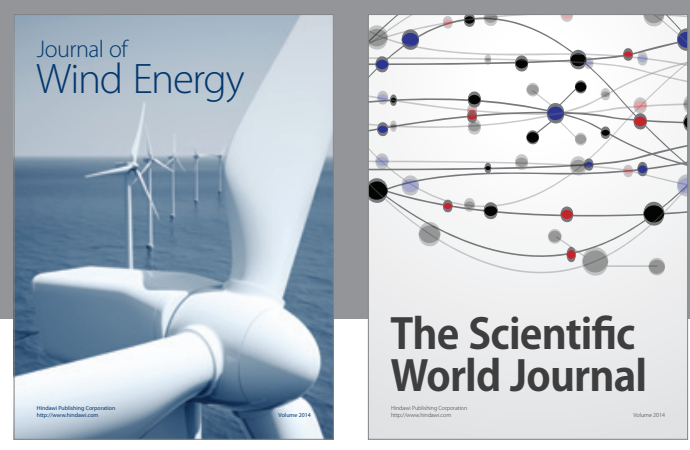

The Scientific World Journal

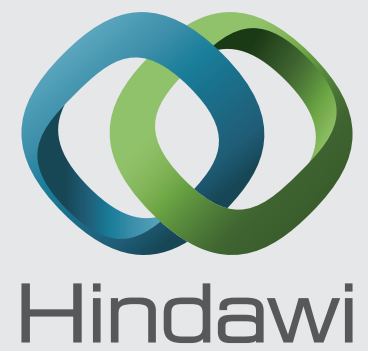

Submit your manuscripts at http://www.hindawi.com
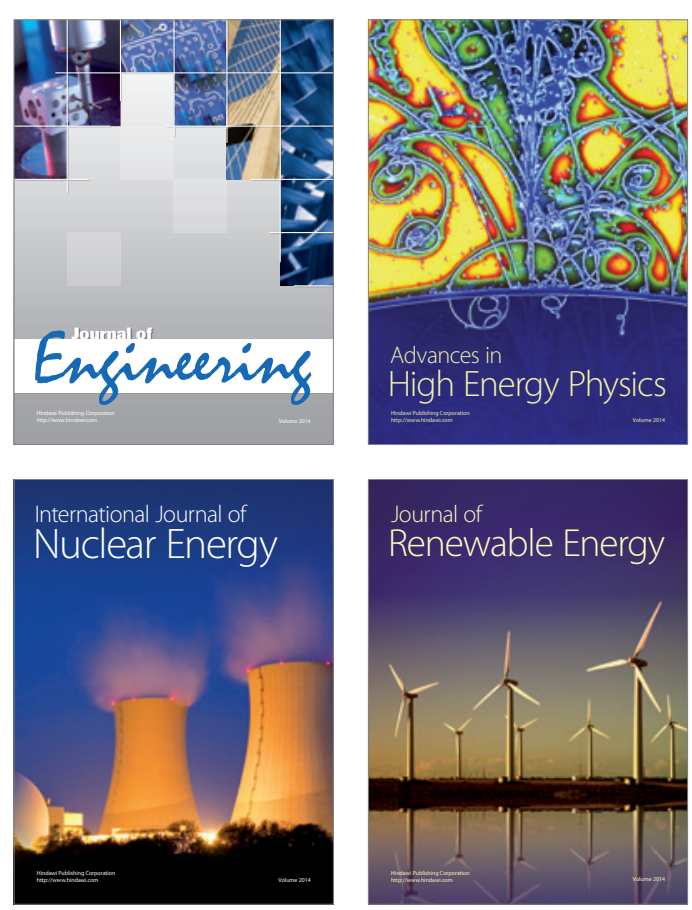

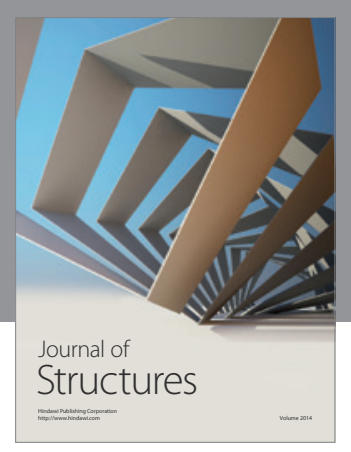

Rotating
Mechinery
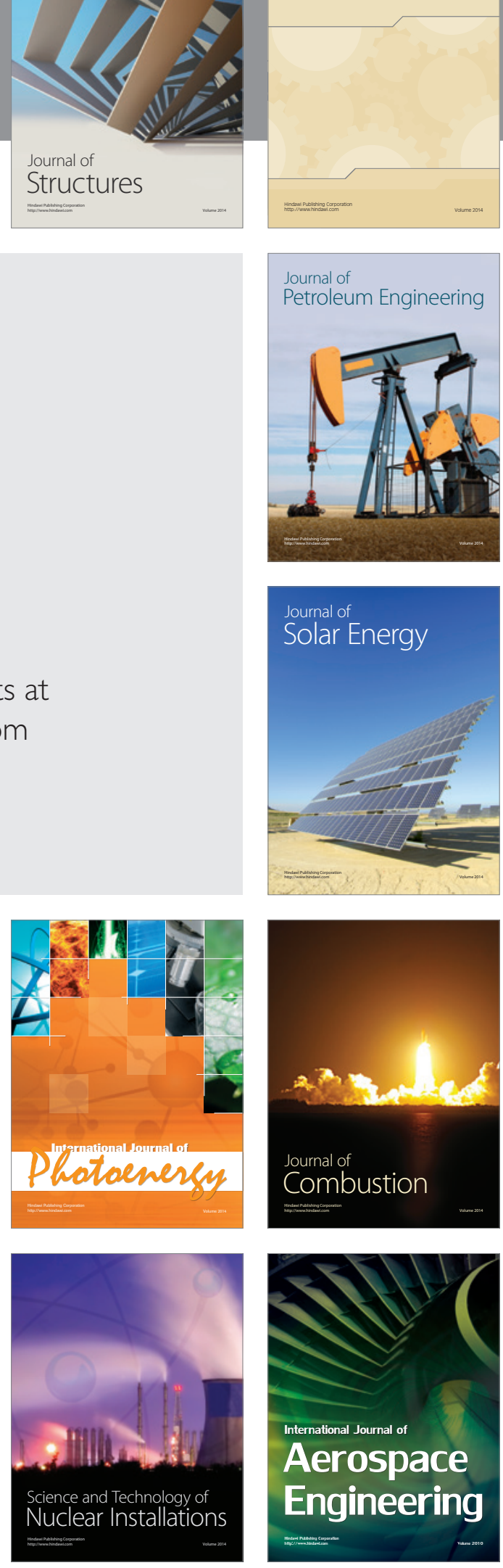